\title{
Simulation: A complex pedagogical space
}

\author{
Donna Rooney \\ University of Technology Sydney \\ Sofia Nyström \\ Linköping University
}

\begin{abstract}
Simulation is a pedagogy that has been widely used in a number of educational settings (e.g., aviation, transport, social work, nursing education). While it can take numerous forms, it often involves an assortment of high-tech equipment (e.g., flight simulators, manikins) that seek to replicate real settings. Specifically, this paper provides an empirically driven exploration of how simulation laboratories, used in the professional education of nurses, and medical and other health professionals in higher education settings, are practised. Informed by sociomaterial understandings, the paper problematises and disrupts homogeneous understandings of the simulation space as found in much of the health sciences literature. This is done by providing a number of layers ranging from accounts of simulation in literature and empirically driven accounts of simulation in action through to more abstract discussion. The paper is attentive to both the distinct materiality of the spaces involved and the human activities the spaces engender. This dual focus enables the consideration of spatial injustices as well as new directions for the development of simulation pedagogies.
\end{abstract}

\section{Introduction}

There is growing awareness of the impact various physical spaces have on student experiences and thus their learning. While education and learning have long been considered in spatial terms (e.g., higher, further, lifelong, lifewide), the idea of learning spaces is currently a key factor in the redesign of much learning and of education. This is occurring in schools (e.g., MakerSpaces, open-plan classrooms), in organisations (e.g., activity-based work, open-plan offices), and in higher education institutions (e.g., flipped classrooms, collaborative classrooms, innovation hubs). It is the physical learning spaces in higher education institutions that are of interest in this paper.

Intensified by demands for authentic learning (Serrano, O’Brien, Roberts, \& Whyte, 2017), among the new spaces found in universities are ones that seek to simulate those found in professional practices. For instance, it is common to find microteaching rooms (teacher education), moot courts (law), and simulation laboratories (nursing, health, and medical education) in contemporary higher education institutions. These transitional spaces are often heralded as providing student teachers, legal, and health professionals with learning experiences that bridge professional education and work (Boud \& Rooney, 2015; Cooper, Orrell, \& Bowden, 2010; Solomon, 2007). Unlike professional placements, these on-campus spaces are said to have capacity for learning experiences to be standardised across cohorts (Issenberg, McGaghie, Petrusa, Lee Gordon, \& Scalese, 2005; Onda, 2012). Further, given the difficulties of securing professional placements in some relevant fields, faculty often consider simulation as an alternative (Arthur, Kable, \& Levett-Jones, 2011; Gaba, 2004; Hayden, Smiley, Alexander, Kardong-Edgren, \& Jeffries, 2014).

Contemporary universities are making significant financial investments in creating these sorts of spaces (Adams Becker et al., 2017; Lasater, 2007) with the assumption that student learning occurs (Finkelstein, Ferris, Weston, \& Winer, 2016). But does investment in infrastructure alone assure learning? We suggest that it is also necessary to understand how these material spaces work together with human activities (including pedagogy) to bring about learning (Carvalho \& Yeoman, 2018). Like Carvalho and Yeoman (2018) and van Merriënboer, McKenney, Cullunan, and Heuer (2017), we agree that learning can be enhanced through the alignment of pedagogy and space. It is in the spirit of such alignment that this paper explores pedagogies of simulation spaces in nursing, medical, and health-related education (henceforth collectively referred to as the health sciences). Using an illustrative empirically driven case study we contribute new insight into how these new learning spaces are practised.

Rather than understanding simulation laboratories as a space within, or stage upon, which learning happens, we seek to explore the interrelationships between simulation pedagogies, learning and these spaces - or as 
Carvalho and Yeoman (2018) suggest the "human-thing dependence" (e. 1). We adopt a socio-material sensibility (Fenwick, 2010; Fenwick, Edwards, \& Sawchuck, 2011), and by doing so we are attentive to a multiplicity of enactments of humans and non-human objects (Fenwick et al., 2011 p. 154). With this as our starting position, we circumvent the smoothing over or ignoring of multiplicity. Rather, our intentions are more to seek them out in effort to present a more nuanced account - one that troubles the normative accounts evident in the bulk of simulation literature and renders "visible the heterogeneous entanglements" (Carvalho \& Yeoman, 2018, e. 1).

As the paper's name suggests, we see simulation laboratories as complex spaces. To work with the multiplicity as well as to provide a measure of coherence for readers, our understanding of simulation spaces is presented via layers - each building upon and/or complicating the one before. We begin this in the first background layer where we use literature to introduce the practice of simulation in the health sciences. We then provide background to the research informing our study before describing how (often overlooked) student observers disrupt homogenous notions of the simulation space. With this background complete, a second layer draws heavily on empirical data to illustrate pedagogy being enacted in the simulation space and tease out very different accounts of students' experiences of it. A third layer then moves to explore the heterogeneous nature of the proximities, materialities, activities, temporalities, and transformations that highlight spatial injustices for some groups of students. Finally, a discussion draws it together. The dual focus on simulation space and pedagogy enables us to consider new directions for the development of simulation pedagogies as well as raise questions around the standardisation of learning.

\section{Layer 1: Background}

\section{Simulation in the health sciences}

The term simulation is broadly defined as the imitation of a process or situation (Nygaard, Courtney, \& Leigh, 2012). For example, in the health sciences the process of suturing may be simulated using real surgical needles, thread, and chicken fillets. A second example is where the process of cardiopulmonary resuscitation (CPR) is simulated using manikins designed for this purpose. Simulating these processes enables students to develop their skills without being open to the life-or-death consequences of getting it wrong if practised on a human patient. This is desirable for the obvious reason that patient safety is of seminal importance to health professionals (Brock et al., 2013; Flanagan, Nestel, \& Joseph, 2004; Kelly \& Jefferies, 2012). Situations with fewer life-or-death consequences are also simulated. For instance, students may practise carrying out a difficult conversation with a patient's family or practise accepted communication protocols in complex emergency situations (Arthur et al., 2011; Brock et al., 2013; Kelly, Forber, Conlon, Roche, \& Stasa, 2014). Some also note simulation's capacity to standardise the educational experiences of the growing student cohorts (Issenberg et al., 2005; Kelly, Hopwood, Rooney, \& Boud, 2016; Onda, 2012). In combination, these warrants for simulation are intensified by the need to address the global shortage of nurses and other health-related professionals (Bucha, Dhillon, \& Campbell, 2017; World Health Organization, 2010).

It is little wonder then that the health sciences have made significant capital investments to create entire learning spaces (commonly called simulation laboratories) that simulate aspects of those found in the professional domain (Arthur et al., 2011; Cook et al., 2011). Notwithstanding low-tech material requirements for simulating suturing or practising communication protocols, it is not uncommon for university faculties to have simulation laboratories that replicate entire hospital wards, including, beds, trolleys, monitors, and a full array of medical equipment, along with expensive high-tech manikins enabled with the capacity to replicate all sorts of human conditions. Such facilities require "major capital investments" (Lasater, 2007, p. 269).

Pedagogically, a cycle of simulation typically follows three phases: briefing, simulation, and debriefing. The three phases of simulation pedagogy encompass different social and material arrangements, which impact on what knowings that is emphasises and students learning in different ways (Ahn, Rimpilainen, Theodorsson, Fenwick, \& Dahlgren, 2015). A scenario/script outlining the circumstances of some medical emergency shapes the simulated action and presupposes the clinical responses that students should decide on (and enact) through correct clinical judgements (Tanner, 2006). 
Simulation has become a signature pedagogy in the health sciences (Lusk \& Fater, 2013). Hence, along with major capital investments in simulation spaces, there has also been significant intellectual investment. This investment culminates in a vast volume of research that evaluates, prescribes, and develops models of simulation pedagogy (Dieckmann \& Ringsted, 2013). The literature speaks to all phases of the simulation cycle, although research that focuses on the simulation itself (Berragen, 2014: Fritz, Gray, \& Flanagan, 2008) and debriefing (Husebø, Dieckmann, Rystedt, \& Friberg, 2013; Levett-Jones \& Lapkin, 2014) is more extensive. There is also a significant number of articles that evaluate aspects of simulation and learning (Cook et al., 2011; Palaganas, Epps, \& Reamer, 2014). Perhaps unsurprising, given the health sciences' relationship with medical science, these evaluations (as well as most other simulation research) are characterised by normative accounts and impoverished theorisations (save the widespread use of some traditional educational theories).

In terms of the simulation space, fidelity is heralded in terms of context (Fritz et al., 2008; Paige \& Daley, 2009) and the scenarios of practice enacted within it (Dieckmann et al., 2007). The more real the better. This realness relates to how the materiality reflects: a practice setting (e.g., a hospital ward, equipment); the human actors involved (e.g., nurses, patients, family members); the medical situation presented (e.g., dropped blood pressure, cardiac arrest); and the activities enacted (e.g., monitoring vital signs, performing $\mathrm{CPR}$, therapeutic touch, professional communication). This striving for the holy grail of fidelity remains largely unchallenged.

An emerging tranche of simulation literature recognises the protocol-driven nature of the aforementioned research and seeks to address simulations' neglect of theoretical groundwork (Berragan, 2014). In particular, Dieckmann has been among the vanguard (Dieckmann, Gaba, \& Rall, 2007; Dieckmann, Molin Friis, Lippert, \& Ostergaard, 2009; Dieckmann \& Ringstead, 2013) and has repeatedly called for new understandings of simulation generated through more theoretical means.

\section{A sociomaterial approach}

Responding to these calls has produced an expansion of conceptualisations of simulation-based education with a growing number of studies providing new perspectives informed by sociomaterial or practice theorisations (e.g., Abrandt Dahlgren, Fenwick, \& Hopwood, 2016; Hopwood, Rooney, Boud, \& Kelly, 2014; Nyström, Dahlberg, Hult, \& Abrandt Dahlgren, 2016a, 2016b; Rooney, Hopwood, Boud, Kelly, 2015). A sociomaterial approach provides a productive lens to disrupt the stable, singular, and normative accounts of these educational spaces. For example, Hopwood et al. (2014) raise epistemological questions about what is actually being simulated. Rooney et al. (2015) present the vignette of students performing CPR in a simulation, while simultaneously kneeling on their patients burned arm, to illustrate how fidelity in a nursing simulation is "never completely stable" (e.11). While such actions would be inappropriate in an emergency ward. The authors posit that in a classroom is it reasonable for educators to overlook some actions if the desired learning outcomes of the lesson is about something else (e.g., professional communication). The assemblage of both professional and educational human roles, relationships, materialities, and activities in the simulation classroom renders fidelity problematic. Referring to the fidelity of a hospitality training program, Solomon (2017, p. 125) concludes that simulation is "its own kind of real". However, we suggest that it is "constantly worked on and produced through the actions and interactions of multiple bodies and objects" (Rooney et al., 2015, e. 11).

It is important to point out that a sociomaterial approach is not a unified one. A sociomaterial approach is the overarching term given to a range of theories: complexity theory, cultural historical activity theory, actor network theory, spatial, and practice theories (Fenwick, Edwards \& Sawchuck, 2001). While these differ in foci and are expressed in different forms and intensities, they share an emphasis on the relational (e.g., between humans as well as between humans and things, knowledges, and/or spaces): decentering the human. The focus of sociomaterial accounts are necessarily multiple, and interest is on how humans, things, knowledges and spaces assemble, and how they work on, with and against one another. By way of example, Nerland and Jenson (2012) investigate the interplay between practices and objects in their exploration of professional work. In doing so, they draw attention to "the role of epistemic objects in the processes of knowing, and, in this respect, to their transformative as well as stabilising effects upon practice” (p. 106).

As its name suggests, the unit of analysis of the practice turn are practices (Hager 2014; Schatzki, 2002; Schatzki, Knorr Centina, \& von Savigny, 2001). This turn is invigorating pre-service professional education 
research with new and interesting ideas concerning what it means to prepare novices for professional practice (e.g., Dall'Alba, 2009; Kemmis et al., 2014; Mahon, Kemmis, Francisco, \& Lloyd, 2017). In simulation pre-service education Nyström et al. (2016a) use practice theory to problematise interprofessional knowings and enactments as a fluid movement between bodily positioning in and out of synchrony in relation to the sociomaterial arrangements of simulation.

Spatial theories challenge the notion of context in ways that refute innocuous understandings. Context is not merely a stage on which human actions are performed. Spatial theorists see spaces as performed, peopled and/or practiced, thus they look for how spaces are made practically intelligible (Schatzki, 2002). Soja (2010) advocates for spatial perspectives that identify "consequential spatiality" (p. 193) and his exploration of bus riders in Los Angeles highlights vast inequalities in the distribution of things, systems, opportunities, and power. Similarly, in education, spatial theories can help draw attention to how learning spaces are assembled "in ways that enable or inhibit learning, create inequalities or exclusions, open or limit possibilities for new practices and knowledge" (Fenwick et al., 2011 p. 129). Furthermore, Massey (1993, p. 155) reminds us that "space is not static (i.e., time-less), nor time space-less", thus connecting space with time. We make use of these ideas to open up new questions about simulation learning spaces, pedagogical practices, and learning. This approach helps us to tease out relationships between activities, things and spaces that might otherwise go unnoticed, as well as identify how the spatial open ups or closes down possibilities for students and learning.

\section{Outline of research studies}

This paper emerges from research carried out by two qualitative studies carried out by two interdisciplinary teams primarily interested in simulation: one in Australia, the other in Sweden. While the studies were independent, similar methodologies and conceptual developments enabled respective research teams to collaborate on various aspects (e.g., Abrandt Dahlgren et al., 2016; Lindh Falk, Hopwood, \& Abrandt Dhalgren, 2017), including this paper. Both the Australian and Swedish studies adopted ethnographic methodologies appropriate for sociomaterial studies (Fenwick et al., 2011, p. 153). Specifically, research methods of both studies included non-participant observation, where multiple researchers observe and make unstructured field notes from various locations across the simulation space (e.g., bedside, control room), as well as locations where student observations, briefing, and debriefing phases are carried out. In addition, multiple locations of simulation space were video and/or audio recorded. Where possible, recordings were transcribed, and in some cases Swedish transcripts translated. Subject documents, including educator and/or student guides were used in desktop research to complement other data. The combination of methods resulted in both studies having rich sets of data which facilitated the combined case study presented below.

In terms of breadth, the combined sample from across both studies consisted of 45 simulation cycles (e.g., briefing, simulation, and debriefing) involved 11 educators and around 350 students. Cycles lasted between 1 and 2 hours, which typically included briefing and debriefing phases of around 12 to 30 minutes. Scenarios in both Sweden and Australia depicted variations of an acute emergency and/or a deteriorating patient condition.

\section{Disrupting homogenous simulation spaces}

In addition to the students who were actively engaged in the simulation action, other human players were involved. One important group were the students who acted as observers. In all the simulation classes we observed as part of this research, student observers were involved. In the Australian study there were 25 to 30 pre-service nursing students in each of the cohorts we studied. They were enrolled in a final year unit focusing on critical care. The semester long unit made use of simulation in some of its 2 hour classes. When simulation was used, 4 to 6 students were assigned acting roles, while the remainder observed. It was possible for students to complete the unit without ever taking an acting role in simulation, although they would likely take acting roles in other units. The Swedish study involved a range of undergraduate health professionals (e.g., medical students, nurses etc.) involved in full day simulations focusing on interprofessional work. Students were asigned to an interprofessional teams of 8 to 10 members and worked together throughout the day. Multiple simulations occured throughout the day and each involved 4 to 6 acting roles, while remaining team members observed. The acting/observer roles were rotated among team members. 
For a number of reasons, not least of all larger cohorts, the observer role is now commonplace in simulation classrooms (Kelly et al., 2016; Nyström et al., 2016b; Rochester et al., 2012). However, despite growing numbers of students observing (rather than acting) in simulations, the observer role is overlooked in the literature. There is, however, some agreement that observation needs to be an active process (Chi, Roy, \& Hausmann, 2008) and active observation can be supported in different ways: by the use of instructional support through individual observational guides (Stegmann, Pilz, Siebeck, \& Fischer, 2012); by the use of collaborative scripts and peer feedback where different roles and tasks are distributed between the active and the observing students (Chi et al., 2008; Zottmann, Dieckmann, Rall, Fischer, \& Tarasow, 2006); and/or by arranging observers into small groups each with a different focus (Kelly et al., 2016).

Returning to our understanding of space, we revised the material space of simulation to include the entirety of physical space(s) in which simulation was enacted. This means that not only the space where students performed CPR was included, but also the spaces where observers were located. In addition, we included the space where the technologies underpinning the simulated action were located. To avoid confusion, forthwith we treat these various (sub)spaces as zones of the entire simulation space.

In our respective studies the simulation spaces were situated in three higher education institutions. While the material arrangements of how simulation were enacted differed slightly across sites, they all could be divided into three zones: an active zone; a control zone; and an observer zone. The active zone was where simulated action takes place; students taking acting roles in the simulation were located here. This zone included hospital beds, medical equipment. and at least one life-sized high-tech manikin with capacity for a pulse and a chest rising and falling as she/he breathed. The manikin was also able to speak with the help of a human and equipment located in the control room (the control zone). Humans located in a control room viewed the simulation action via one-way windows. From the control room a technician controlled the technology enabling changes in the manikin as well as the video equipment that relayed the video into the observer zone where student observers were located. The observer zone was either a separate room altogether, or in the same room as the active zone but separated by a partition. In either setup, the observer zone was typically furnished with student seating and a video screen. The simulation space consisted of the entanglement of multiple yet interdependent materialities, humans, activities, and zones that coproduced the simulation laboratory. Acting students moved across the various zones during various phases of the simulation cycle. All the Australian, and some Swedish, observers remained in the observer zone and watched simulation action relayed to a screen. Some other Swedish observers observed through a one-way window from the control zone.

\section{Layer 2: Pedagogy enacted in the simulation space}

Having provided background, this section turns to empirical data to illustrate pedagogy. Our empirical illustration follows the phases of simulation enacted across the various zones. We begin with the briefing phase where the educators' pedagogical interventions prepared the students for the ensuing experience - or to use Boud and Walkers' (1990) words, how students are "introduced to the learning situation" and what, if any, relevant aspects are "pointed to" (p. 73). Adhering to the general rythm of the simulation cycle (seen in Layer 1), each simulation began with a briefing phase where the scenario was introduced to the class before the acting or observing roles were assigned. Once assigned, some students moved into their respective zones. Role cards provided acting students with information about their role and then a technical briefing further prepared them by providing information about the functionality of the manikins and where they could locate particular medical equipment and other objects they might require (e.g., phones to call doctors). In most cases, acting students were also provided with clothing items (e.g., uniforms, hats, other accessories) to help them get into character.

Toward the end of the briefing phase attention was redirected toward observers. We noted various ways the observing students were invited to engage in the forthcoming happenings. In most cases, very short instructions were given, for example: "So while [the simulation] is happening the rest of you are going to sit here quietly and watch the simulation on the screen." This briefing exemplified the limited activities expected of observers: sitting quietly and watching. That said, there were some observer briefings where the educator justified the observer role and framed it as a learning opportunity.

Observer briefings did not always include verbal instructions about what to take notice of, however when there were, observers were directed to notice for example, how teams of acting students worked together, 
team leadership, or how clinical skills were performed. Implied was an expectation that observers would provide feedback to their acting peers. While written observation guides were available their use was varied. In some instances, the educator distributed these during the briefing without providing instructions about how they should be used. In other instances, they were available electronically before the class with an assumption that students would print them and bring them to class. Verbal briefings of observers sometimes included instructions about what was expected of them in the forthcoming debriefing phase:

[After the simulated action], we're going to gather back together as a group and the people that have participated are going to get a chance to talk about the experience. Then the observers are going to have a chance to then make some comments.

With the briefing complete, the actual simulation phase began. Those in the active zones now made decisions about the unfolding clinical situation, decided on and performed various clinical skills, and communicated with other actors (i.e., team members, the patient, and the patient's family). It was common for the educator to be part of the acting team too (e.g., taking the role of doctor). The doctor often narrated what was occurring, for example: "So he's got bruising on the left side of his chest [...] and he's got burns to his right arm." These sorts of narrations were audible to both acting and observing students alike as was the talk between acting students/nurses.

As simulated activity ramped up in the acting zone, activies in the observer zone were more relaxed and largely confined to (sanctioned) sitting quietly and watching the screen. A few observation guides were on desks or laps, but were rarely used. When observers were working in small groups there was some pointing to the screen and whispering, which suggested students were discussing some aspect of what they were observing. Unsanctioned activities were also noted when observers were not accompanied by an educator, for example: using mobile phones, grooming, and sleeping. Where the observers were accompanied by an educator (i.e., when they were located in the control zone), educator questioning prompted discussions around some aspect of what was being observed.

Once the scenario came to an end, the third phase of simulation (debriefing) began. Here the initial setting up of the briefing phase more or less came to fruition. The cohorts gathered back together. The Australian group acting students re-entered their observer zone. The Swedish student group re-entered their observer zone or a larger room where the briefing was held.

Once the cohort was reassembled, the people who participated had the opportunity to discuss their experiences. Educator-led debriefing phases began by focusing on the acting students' experiences. Debriefings exemplified the debriefing steps seen in the established simulation literature: (1) reflecting, (2) noticing, (3) interpreting, (4) responding, and (5) reflecting (Lusk \& Fater, 2013, p. 18). Following this, observers were able to comment when the educator asked general questions such as: "What do you think?", "Thoughts?", and "How do you think that went?". Such questions typically generated short responses such as "Good" or a brief comment about what an acting students did well. It was not uncommon for just one or two observing students to speak during each debriefing. The example below shows an observers' contribution being folded into the debriefing:

Facilitator: How do you think that went?

Acting student: I lost track of time.

Facilitator: You think it was quick?

Acting student: Yes.

Facilitator: Now, those who were observing, how did you think the time sequence went?

Observing student: Slow

[Facilitator expands on this point ...]

Facilitator: So we need to wrap up very quickly...

The contrasting experiences of time across the zones and phases of the simulation cycle provide a helpful segue to consider snapshots of some typical students' experiences in the simulation spaces we investigated.

1. Student A arrives at her class in the simulation laboratory. The educator gives the entire class a broad introduction to what will be happening. Student A is relocated to the acting zone where she is briefed in more detail about what is expected of her in the forthcoming activity. The student 
carries out the activity which requires her to perform a number of practices, and apply a number of concepts, that she has been learning about in a scenario of professional practice. When the activity is complete she re-joins her classmates where she is prompted to describe, reflect on, and learn from, her experience through a 20 minute educator led debriefing phase. Class is dismissed.

2. Student B arrives at her class in the simulation laboratory. The educator gives the entire class a broad introduction to what will be happening. Student B is then directed to sit quietly and watch the video screen in the observer zone. The educator disappears for around 40 minutes. During this time Student B fumbles through her bag, checks her mobile, and talks softly with her classmates. Once a video appears on the screen she sporadically watches it while continuing her earlier activities. The educators' reappearance marks the beginning of the debriefing phase, consisting of a 20 minute discussion with a group of her peers. Finally, the educator asks Student B and the other observers "What did you think?" One student (not Student B) says "Good". Class is dismissed.

3. Student $\mathrm{C}$ arrives at her class in the simulation laboratory. The educator gives the entire class a broad introduction to what will be happening. Student $\mathrm{C}$ is allocated to an interdisciplinary team: a group of students she will work with over the day. Student C's first experience of the simulation cycle is similar to Student B's located in either the observer zone or the control/oberserver zone. In the next cycle her experience is similar to Student A's. This cycle of simulation cycles continues until the class is dismissed.

These typical enactments of the simulation zones and phases highlighted important differences in the overall simulation space. Folding in this empirical layer, we shift our understanding of the simulation space yet again - to one of spaces of difference.

\section{Layer 3: Spaces of difference}

Several features of the simulation learning space were shared by all students. For instance, the students had similar desires (e.g., to become health or medical practitioners), their professional education was more or less similar, and they shared the overarching experience of being students in a nursing or medical preservice program, including being enrolled in a unit that makes use of simulation pedagogy. Both acting students and oberservers also shared having their learning shaped by the same scenario/script that has been designed for the simulated activity. But as the snapshots above illustrate, there were some important differences for learning that were afforded by the zones in which students were positioned during the simulation cycle. Despite learning being the object for all students in the simulation classroom, the spatial affordances of various zones resulted in differences in terms of roles and relationships, proximities, materialities, activities, and time. While both the acting students and the observing students were embedded in social roles and relationships and physically engaged with the materiality of the zone they were located within, their proximities to the simulated action (the locus of learning) were different.

The available roles for students in the acting zone were as nurses, patients, and patient family members, and this also meant being enmeshed in multiple social and professional relationships. Entangled with these roles and relationships was the materiality of the active zone - resembling that found in a professional settings and yet nested in the broader educational institution. The only available roles in the observer zone were as students, limiting the social relationships to one of peers (and student/educator for some observers). Within these roles and relationships was the materiality of observer zone - resembling the educational setting found more broadly in the educational institution in which the observer zone was nested. The materiality of the control zone, and in particular the technologies, contained roles of disembodied patients and doctors.

Proximity and the sociomaterial arrangements of each zone also "open[ed] up or limit[ed]" the kinds of activities posible (Fenwick et al., 2011, p. 129). For instance, while all could physically touch the material setting of the zones they were located within, visceral engagement with the locus of learning (the unfolding simulation and its materiality) was only opened up for students bodily embeded in acting zones. Further interrogation of possible activities across the zones could also shed light on how and why certain activities become practically intelligible: that is more or less likely to happen (Schatzki, 2002). The human activities in the acting zone resembled those from professional settings (e.g., monitoring blood pressure, performing 
CPR), whereas human activities in observer zones resembled those found in typical educational settings (e.g., note-taking, listening to an educator, being stimulated by some form of content). It was notable how blood pressure machines, manikins, note-pads, and video technologies were agentic in opening up possibilities for activities to happen.

Activities were shaped not only by objects within the zone, but also by mediating objects that infused and circulated across multiple zones, for instance, the scenario/script and observation guides. Both were products of curriculum design with the purpose of bringing about learning, and as such they embodied the learning outcomes for the entire class. The scenario/script manifested in various objects (e.g., role cards, handover scripts, patient history records) made physically available to acting students who used them to enact the performance that was observed by students in other zones. These scenario/scripts embodied some sort of medical situation presupposing how acting students might notice and intervene. That is, it shaped acting students' actions in order that all students learned. They were informed by both professional and educational practice. The focus of observers was typically to evaluate acting students' performances. Observation guides generally manifested as student handouts or electronic documents made available to observing students. Their purpose was to direct what observers were to notice and to bring about learning (e.g., Chi et al., 2008). While the content of observation guides was professional practice, the design was primarily informed by education practices. Notwithstanding instances where an additional educator accompanied observers, the observation guides acted as proxies for absent pedagogues. While observer guides had potential to circulate across the multiple zones, and influence activities in various simulation phases, this was not generally realised. Additional curriculum objects (e.g., the simulation plan for a patient's deteriorating condition) were made available to educators or control-room technicians. These impacted both the active and observer zones, but in different ways. For instance, they triggered particular events (e.g., a drop in the manikin's blood pressure signifying cardiac arrest) that acting students were required to notice and respond to (e.g., perform CPR) - a performance that was observed by others in another zone. However, opening up opportunities so that particular activities might happen, did not ensure they happened.

In the simulation cycles we studied there were also examples where prescribed activities did not ensue in the presupposed manner. Pedagogical interventions were used to direct and redirect student activities. These interventions impacted students in different ways. For instance, many educators appeared to "notice out aloud" (Rooney \& Boud, in press) during the simulation phase. This involved educators (in their doctor role) narrating an unfolding situation. To use an example mentioned earlier: "So he's got bruising on the left side of his chest, [...] and he's got burns to his right arm." Both acting and observing students could hear this narration and thus be (re)directed to notice some pivotal clinical moment arising in the simulation requiring them to act. Students in the acting zone were required to notice this moment in the midst of practice and use their developing clinical judgment to respond to the unfolding situation. Observers, on the other hand, may have been prompted by the naration to notice this moment and (perhaps) to imagine how best to intervene if a similar situation were to arise for them.

Again this drew attention to the temporal differences between the zones and their precariousness. Like all spaces, the acting zone was only performed for the duation of the simulation phase. Acting students temporarily positioned their activities within the professional practice they were training for (if only for the duration of the simulation) and acted as if they were already practitioners, whereas for observers the professional practice was in the future. Some participants crossed between zones in the same lesson speeding up or slowing down action at different moments. The arrangements of the units involved meant students could be assigned a different role in another zone at another time. However, there were no guarentees that this would be the case.

\section{Concluding discussion: Complex spaces}

With an understanding of simulation laboratory as spaces of difference, we now tentatively consider spatial injustices (Soja, 2010). More broadly, where there are differences there are also inequalities. But how are these differences to be understood, let alone resolved? Do spatial injustices limit learning opportunities for students in the observing zone? Does the overwhelming focus on the learning of students in the active zone overshadow that of the observers? In response to these questions we might, on the one hand, conclude that observers are being short-changed. For example, our layers of simulation pedagogies may appear to illustrate how the majority of the teachers' time in the simulation laboratory is devoted to the students 
delegated active roles, while observers appear overlooked. On the other hand, we might construct a different argument, where it is the students in the active zone who are subject to injustice. After all, it is the performance of the small group of students in the acting zone that provide the locus for observers' learning. Does simulation pedagogy only appear to be about the actors' learning when, in fact, the actors are merely proxies so that the observers might learn? These are all interesting perspectives, but ones we have not reconciled. What we can see, however, is that the standarisation of learning becomes inplausible and that there is value in asking new questions about simulation pedagogies.

Our accounts of the simulation laboratory have presented it as a space of flux. Role cards, scenarios, and various clothing items transform students into real professionals (albeit temporarily). Educators transform into doctors who managed patient conditions and orchestrate attending nurses, yet they simultaneously remain educators who direct observing students' focus at pivotal moments. The simulation space is therefore not only a space where humans transform, but where humans and human activity transform the space as well. Time speeds up for some and down for others in the very same space. Once briefed and dressed, student/nurses performing CPR on a manikin/patient transform the ostensible educational space into a hospital ward, before debriefing returns nurses to students, and doctors to educators. Yet even these roles are unstable. When observers enter the control zone with disembodied students there is a merger of zones for the duration of the simulation. But it is not only the humans and activities that shape the simulation space. Our layered accounts illustrate how objects have agency too. As Fenwick et al. (2001) rightly insist, observation guides, scenario/scripts, medical equiptment, and desks, all shape possible actions as well as confirm (or deny) temporary subjectivities and/or relationships. Transformations are assisted by the materiality of technologies and objects endemic in both the professional and educational domains. As Fenwick (2010) would say, "stuff matters", yet it is often overshadowed in research accounts by the preoccupations of understanding human activity and meaning making.

In contrast to the homogeneous perceptions of simulation laboratories seen in much of the health sciences literature, our layering of the simulation space, informed through a sociomaterial lens, sees it as more complex. We have illustrated how the multiple nature of the simulation space (zones) must work together to open up possibilities for learning in the simulation laboratory. In contrast to extant literature that often focuses on one zone in isolation, we suggest it more helpful to consider the entanglement of roles, relationships, activities, and materialities across all zones. This multiple focus is complex for researchers as well as for simulation educators.

This returns us to the role of pedagogy. A sociomaterial understanding of interdependent learning zones in the simulation spaces draws attention to differences for all involved: including educators. These are complex educational spaces. But then how might space and pedagogy align when these precarious simulation spaces are understood as complex? What designable elements (Carvalhoa \& Yeoman, 2018) might support learning? Teaching in these spaces is demanding for educators who must have multiple foci if they are to support all students' learning. We propose that a deeper understanding of the simulation space may help educators develop pedagogical interventions, that further open up opportunies for all student learning, by raising questions about simulation that have hitherto gone unasked. Aligning these complex simulation spaces with pedagogies is likely to require complex pedagogies generated by more complex questions. We do not pose these here, but as Bauman (2005) so poignantly suggested, we see merit in not arriving at definitive answers, but by remaining open to asking new sorts of questions. However, the layered account of the simulation space presented here, may provide impetus for others to do so.

\section{Acknowledgement}

The authors sincerely thank the peer-reviewers for their thoughtful comments and helpful suggestions in regard to strengthening this paper.

\section{References}

Abrandt Dahlgren, M., Fenwick, T. \& Hopwood, N. (2016). Theorising simulation in higher education: Difficulty for learners as an emergent phenomenon, Teaching in Higher Education, 6(21), 613-627. https://doi.org/10.1080/13562517.2016.1183620 
Adams Becker, A., Cummins, M., Davis, A., Freeman, A., Hall Giesinger, C., \& Ananthanrayanan, V. (2017). NMC Horizon Report 2017 Higher Education Edition. Austin, TX: The New Media Consortium.

Ahn, S., Rimpiläinen, S., Theodorsson, A., Fenwick, T., \& Dahlgren, M. A. (2015). Learning in technology-enhanced medical simulation: Locations and knowings. Professions \& Professionalism, 5(3), e1-e12. https://doi.org/10.7577/pp.973

Arthur, C., Kable, A., \& Levett-Jones, T. (2011). Human patient simulation manikins and information communication technology use in Australian schools of nursing: A cross-sectional survey. Clinical Simulation in Nursing, 7(6), e219-e227. https://doi.org/10.1016/j.ecns.2010.03.002

Bauman, Z. (2005). Education in liquid modernity. The Review of Education, Pedagogy, and Cultural Studies, 27(4), 303-317. https://doi.org/10.1080/10714410500338873

Berragan, L. (2014). Learning through simulation: A case study approach towards an expansive model of learning. Nurse Education Today, 34(8), 1143-1148. https://doi.org/10.1016/j.nedt.2014.03.005

Boud, D., \& Rooney, D. (2015). What can higher education learn from the workplace? In A. DaileyHerbert \& K. Dennis (Eds.), Transformative perspectives and processes in higher education (pp. $195-$ 210). Dordrecht: Springer International Publishing.

Boud, D., \& Walker, D. (1990). Learning from experience: Using experience for learning. Buckingham: Open University Press.

Brock, D, Abu-Rish, E., Chui, C., Hammer, D., Wilson, S. Vorvivk, L. ... Zierlet, B. (2013). Republished: Interprofessional education in team communication: Working together to improve patient safety. Postgraduate Medical Journal, 89(1057), 642-651. https://doi.org/10.1136/postgradmedj-2012-000952rep

Bucha, J., Dhillon, I., \& Campbell, J. (Eds.) (2017). Health employment and economic growth: An evidence base. Geneva: World Health Organization.

Carvalho, L., \& Yeoman, P. (2018). Framing learning entanglement in innovative learning spaces: connecting theory, design and practice. British Educational Research Journal, 44(6), 1-18. https://doi.org/10.1002/berj.3483

Chi, M. T. H., Roy, M., \& Hausmann, R. G. M. (2008). Observing tutorial dialogues collaboratively: Insights about human tutoring effectiveness from vicarious learning. Cognitive Science, 32(2), 301341. https://doi.org/10.1080/03640210701863396

Cook, D. A., Hatala, R., Brydges, R., Zendejas, B., Szostek, J. H., Wang, A. T. ... Hamstra, S. J. (2011). Technology-enhanced simulation for health professions education: A systematic review and metaanalysis. JAMA, 7, 306(9), 978-988,]. https://doi.org/10.1001/jama.2011.1234

Cooper, L., Orrell, J., \& Bowden, M. (2010). Work Integrated Learning: A guide to effective practice. Abingdon: Routledge.

Dall'Alba, G. (2009). Learning to be professionals: Innovation and change in professional education. Dordrecht: Springer.

Dieckmann, P., Gaba, D., \& Rall, M. (2007). Deepening the theoretical foundations of patient simulation as social practice. Simulation in Healthcare, 2(3), 183-193. https://doi.org/10.1097/SIH.0b013e3180f637f5

Dieckmann, P., Molin Friis, S., Lippert, A., \& Østergaard, D. (2009). The art and science of debriefing in simulation: Ideal and practice. Medical Teacher, 31(7), 287-294. https://doi.org/10.1080/01421590902866218

Dieckmann, P., \& Ringsted, C. (2013). Pedagogy in simulation-based training in healthcare. In Forrest, K., McKimm, J. \& S. Edgar (eds). Essential Simulation in Clinical Education, Oxford: John Wiley \& Sons, e43-58. https://doi.org/10.1002/9781118748039.ch4

Fenwick, T. (2010). Re-thinking the "thing." Socio-material approaches to understanding and researching learning in work. Journal of Workplace Learning, 22(1/2), 104-116. https://doi.org/10.1108/13665621011012898

Fenwick, T., Edwards, R., \& Sawchuck, P. (2011). Emerging approaches to educational research: tracing the socio-material. Abingdon: Routledge.

Finkelstein, A., Ferris, J., Weston, C., \& Winer, L. (2016). Research-informed principles for (re)designing teaching and learning spaces. Journal of Learning Spaces, 5(1), 26-40.

Flanagan, B., Nestel, D., \& Joseph, M. (2004). Making patient safety the focus: Crisis resource management in the undergraduate curriculum. Medical Education, 38(1), 56-66.

https://doi.org/10.1111/j.1365-2923.2004.01701.x 
Fritz, P. Z., Gray, T., \& Flanagan, B. (2008). Review of mannequin-based high-fidelity simulation in emergency medicine. Emergency Medicine Australasia, 20(1), 1-9. https://doi.org/10.1111/j.17426723.2007.01022.x

Gaba, D. M. (2004). The future vision of simulation in health care. Quality and Safety in Health Care, 13(1), i2-i10. https://doi.org/10.1136/qshc.2004.009878

Hager, P. (2014). Practice as a key idea in understanding work-based learning. In P. Gibbs (Ed.), Learning, work and practice: New understandings (pp. 85-106). Dordrecht: Springer.

Hayden, J. K., Smiley, R. A., Alexander, M., Kardong-Edgren, S., \& Jeffries, P. R. (2014). The NCSBN national simulation study: A longitudinal, randomized, controlled study replacing clinical hours with simulation in prelicensure nursing education. Journal of Nursing Regulation, 5(2), 1-64, https://doi.org/10.1016/S2155-8256(15)30062-4

Hopwood, N., Rooney, D., Boud, D., \& Kelly, M. (2014). Simulation in higher education: A sociomaterial view. Educational Philosophy and Theory, 48(2), 165-178. https://doi.org/10.1080/00131857.2014.971403

Husebø, D., Dieckmann, P., Rystedt, H., \& Friberg, F. (2013). The relationship between facilitators' questions and the level of reflection in the post-simulation debriefing. Simulation in Healthcare, $8(3)$, 135-142. https://doi.org/10.1097/SIH.0b013e31827cbb5c

Issenberg, S. B., McGaghie, W. C., Petrusa, E. R., Lee Gordon, D., \& Scalese, R. J. (2005). Features and uses of high-fidelity medical simulations that lead to effective learning: A BEME systematic review. Medical Teacher, 27(1), 10-28. https://doi.org/10.1080/01421590500046924

Kelly, M. A., Forber, J., Conlon, L., Roche, M., \& Stasa, H. (2014). Empowering the registered nurses of tomorrow: Students' perspectives of a simulation experience for recognising and managing a deteriorating patient. Nurse Education Today, 34(5), 724-729. https://doi.org/10.1016/j.nedt.2013.08.014

Kelly, M. A., Hopwood, N., Rooney, D., \& Boud, D. (2016). Enhancing students' learning through simulation: Dealing with diverse, large cohorts. Clinical Simulation in Nursing, 12(5), 171-176. https://doi.org/10.1016/j.ecns.2016.01.010

Kelly, M. A., \& Jeffries, P. (2012). Clinical simulation in health care - Contemporary learning for safety and practice. Collegian, 19(3), 115-117. https://doi.org/10.1016/j.colegn.2012.07.002

Kemmis, S., Wilkinson, J., Edwards-Groves, C., Hardy, I., Grootenboer, P., \& Bristol, L. (2014). Changing practices, changing education. Singapore: Springer.

Lasater, K. (2007). High-fidelity simulation and the development of clinical judgment: Students' experiences. Journal of Nursing Education, 46(6), 269-276.

Levett-Jones, T., \& S. Lapkin (2014). A systematic review of the effectiveness of simulation debriefing in health professional education. Nurse Educator Today, 34(6). 58-63.

Lindh Falk, A., Hopwood, N., \& Abrandt Dahlgren, M. (2017). Unfolding practices: A sociomaterial view of interprofessional collaboration in health care. Professions and Professionalism, 7(2). e1699$e 1699$.

Lusk, J., \& Fater, K. (2013). Postsimulation debriefing to maximize clinical judgement development, Nurse Educator, 1(38), 16-19. https://doi.org/10.1097/NNE.0b013e318276df8b

Mahon, K., Kemmis, S., Francisco, S., \& Lloyd, A. (2017). Introduction: practice theory and the theory of practice architectures. In K. Mahon, J. Kaakinen, S. Francisco, S. Kemmis, \& A. Lloyd (Eds.), Exploring educational and professional practice: Through the lens of practice architectures (pp. 130). Singapore: Springer.

Massey, D. (1993). Politics and space/time. In S. Pile, \& M. Keith (Eds.), Place and the politics of identity (pp. 139-159). London: Routledge.

Nerland, M., \& Jenson, K. (2012). Epistemic practices and object relations in professional work. Journal of Education and Work, 25(1), 101-120, https://doi.org/10.1080/13639080.2012.644909

Nygaard, C., Courtney, N., \& Leigh, E. (Eds.) (2012). Simulations, games and role play in university education. United Kingdom: Libri Publishing.

Nyström, S., Dahlberg, J., Hult, H., \& Abrandt Dahlgren, M. (2016a). Enacting simulation: A sociomaterial perspective on students' interprofessional collaboration. Journal of interprofessional care, 30(4), 441-447. https://doi.org/10.3109/13561820.2016.1152234

Nyström, S., Dahlberg, J., Hult, H., \& Abrandt Dahlgren, M. (2016b). Observing of interprofessional collaboration in simulation: A socio-material approach. Journal of interprofessional care, 30(6), 710 716. https://doi.org/10.1080/13561820.2016.1203297

Onda, E. (2012). Situated cognition: its relationship to simulation in nursing education. Clinical Simulation in Nursing, 8(7), 273-280. https://doi.org/10.1016/j.ecns.2010.11.004 
Paige, J. \& Daley, B. (2009) Situated cognition: a learning framework to support and guide high-fidelity simulation. Clinical Simulation in Nursing, 5(3), 97-103. https://doi.org/10.1016/j.ecns.2010.11.004

Palaganas, J. C., Epps, C., \& Reamer, D. (2014). A history of simulation-enhanced interprofessional education. Journal of Interprofessional Care, 28(2), 110-115. https://doi.org/10.3109/13561820.2013.869198

Rochester, S., Kelly, M., Disler, R., White, H., Forber, J., \& Matiuk, S. (2012). Providing simulation experiences of large cohorts of 1 st year nursing students: Evaluating quality and impact. Collegian, 19(3), 117-125. https://doi.org/10.1016/j.colegn.2012.05.004

Rooney, D., Hopwood, N., Boud, D., \& Kelly, M. (2015). The role of simulation in pedagogies of higher education for the health professions: Through a practice-based lens. Vocations and Learning. 8(3), 269-285. https://doi.org/10.1007/s12186-015-9138-z

Rooney, D. \& Boud, D. (in press) Vocations and Learning

Serrano, M., O’Brien, M., Roberts, K., \& Whyte, D. (2017). Critical pedagogy and assessment in higher education: The ideal 'authenticity' in learning. Active learning in Higher Education, 19(1), 9-21. https://doi.org/10.1171/1774/6194679878471471772233244

Schatzki, T. R. (2002), The site of the social: A philosophical account of the constitution of social life and change, University Park, PA: Pennsylvania State University Press.

Schatzki, T. R., Knorr Centina, K., \& von Savigny, E. (Eds.) (2001). The practice turn in contemporary theory. New York, NY: Routeledge.

Soja, E. (2010). Seeking spatial justice. Minneappolis, MN: University of Minnesota Press.

Solomon, N. (2007). Reality bites: Bringing the 'real' world of work into educational classrooms. In M. Osborne, M. Houston, \& N. Toman (Eds.), The pedagogy of lifelong learning: understanding effective teaching and learning in diverse contexts (pp. 115-126). London: Routledge.

Stegmann, K., Pilz, F., Siebeck, M., \& Fischer, F. (2012). Vicarious learning during simulations: Is it more effective then hands-on training? Medical Education, 46(10), 1001-1008. https://doi.org/10.1111/j.1365-2923.2012.04344.x

Tanner, C. (2006). Thinking like a nurse: A researched-based model of clinical judgment in nursing. Journal of Nursing Education, 45(6), 204-211.

van Merriënboer, J., McKenney, S., Cullinan, D., \& Heuer, J. (2017). Aligning pedagogy with physical learning spaces. European Journal of Education, 52(3), 247-252. https://doi.org/ 10.1111/ejed.12225

World Health Organization (2010). Framework for action on interprofessional education and collaborative practice. Geneva, Switzerland: Author.

Zottmann, J., Dieckmann, P., Rall, M., Fischer, F., \& Tarasow, T. (2006). Fostering simulation-based learning in medical education with collaboration scripts. Simulation in Healthcare, 1(3), 193-193. https://doi.org/10.1097/ 01266021-200600130-00055

Corresponding author: Donna Rooney, Donna.Rooney@uts.edu.au

Australasian Journal of Educational Technology (C) 2018.

Please cite as: Rooney, D., \& Nyström, S. (2018). Simulation: A complex pedagogical space. Australasian Journal of Educational Technology, 34(6), 53-64. https://doi.org/10.14742/ajet.4470 